\title{
CONCEPT OF COMPUTER-AIDED ASSESSMENT OF THE TECHNICAL CONDITION OF OPERATED GAS TURBINE VANES
}

\author{
Mariusz Bogdan ${ }^{1}$ \\ Marcin Derlatka ${ }^{1}$ \\ Józef Błachnio ${ }^{2}$ \\ ${ }^{1}$ Bialystok Technical University, Poland \\ ${ }^{2}$ Air Force Institute of Technology, Poland
}

\begin{abstract}
The article presents a multi-stage algorithm for automatic (without any human, user - diagnostician intervention) detection of vanes-blades (technical objects) and their surfaces on a digital image, combined with color analysis, aimed at determining the technical condition of the tested turbine elements. The images recorded with the use of a camera, containing previously dismantled from the turbine operated stator vanes, were used as the exemplary analysis material. The paper presents the algorithm for the detection of the vanes' airfoil surfaces with the impact of the applied techniques and methods of image processing and analysis on the final result (software localization of the vane's trailing and leading edge), Then, the obtained image data, including the structural changes of both the vane's coating and material (metallographic testing) were correlated with the surface colour scheme (colour segmentation based on the $\mathrm{YCbrCr}$ colour space model). Thanks to this approach, areas on the surface of the blade were distinguished, characteristic for proper, overheated and transient condition.
\end{abstract}

Keywords: gas turbine, condition assessment, vanes (blades), coating, surface colour

\section{INTRODUCTION}

While operating a turbine engine, no matter whether an aircraft, a marine or a traction one, various failures to engine assemblies occur. The predominant majority of failures to gas turbine vanes (blades) are effected with inappropriate operation (misadjustment) of subassemblies mating with the turbine, first of all, the combustion chamber [8] and, like with turbines of aircraft turbojet engines, the exhaust nozzle (in particular, the mechanism to adjust nozzle-mouth cross-section) $[1,12]$. The detection of gas turbine subassembly damage during operation is possible during periodic inspection by way of assessing the condition of blade and vane rings' surfaces, their mounting elements and interstage turbine sealings etc. $[7,13,22]$. In multi-stage turbines, the visual assessment of the first turbine stage is relatively easy to carry out when the combustion chamber assembly is disassembled. The intermediary stages and the last stage are inspected without the need of disassembly, by using fibre optic viewing devices (videoscopes) $[11,15]$. The damage of initial turbine stages are usually caused by the impact of high temperature exhaust fumes, whereas the damage of the last stages (with the longest blades) - by the impact of mechanical load (vibration, centrifugal force) $[10,22]$. The frequent cause of damage is material overheating and thermal fatigue of the thermal fatigue of the vanes' nozzle apparatus and rotor blades, resulting from both the excessive temperature and the time the blade (vane) is exposed to high temperature and the chemical activity of exhaust fumes (the entire operation process features a change in the colour of the vane-blade leaf) [19]. The minimisation of the safety hazard of engine operation requires periodical inspection of the vanes'/blades' technical condition. Overhauls and inspections feature blade checks using classic NDT (nondestructive testing) methods, i.e. visual inspection, fluorescent, magnetic and eddy current flaw detection $[5,16,18]$, or rapidly developing measurement techniques related to thermography 
and tomography $[3,14]$. Each of the aforementioned NDT methods is executed in specific conditions and the information obtained regards the tested turbine element's flaw and damage types specific (characteristic) for each method. Furthermore, their execution requires extensive theoretical knowledge and experience of the diagnostician, because the diagnostic information acquired by applying them is often encumbered with certain complications of result interpretation and limited reliability when compared to destructive methods [19]. The overheating of the blade material, especially of uncooled blades, constitutes damage that is most difficult to identify and technical condition most difficult to classify. Thus far, only the eddy current method gives certain capabilities of detecting the degree of blade material overheating, but it is strongly dependent on many factors, including, among others: type of blade material and protective coating, applied measurement instrumentation and parameters, and it has not yet been confirmed on an adequate statistical sample [14]. Therefore, there is still a lack of reliable method of detecting structural changes after the impact of high temperature exhaust fumes. Despite the fact that the destructive methods (e.g. metallographic method) provide much more information about the structure of the tested turbine element's material, they make its further use impossible, thereby increasing the overall costs.

Progressive damage cause by material overheating leads to faulty gas turbine operation and sometimes, as in the case of aircraft jet motors, to tragic accidents. This type of damage is always removed by overhauling the motor, which in case of aviation results in very high costs of approx. PLN 2-5 million, depending on the motor type. Therefore, the costs of motor overhaul are 1.000-3.000 times higher when compared to the value of a turbine rotor blade, for example. The decision about the need of motor overhaul is currently made by the diagnostician, who can diagnose the condition of hard to reach turbine elements by applying the visual method with the use of a videoscope. The condition assessment is executed based on the recorded image of the diagnosed element's surface and by comparing the image with the model surface images of fit and unfit analogous turbine blade elements. Such condition assessment criteria are very subjective, because they depend on the diagnostician's state of knowledge and sight. The diagnostician's decision can be verified using the destructive method. The tested element undergoes analysis of the micro-structure based on a metallographic sample. Mistakes of the diagnostician's subjective assessment can lead to deeming an overheated blade as fit or not overheated as unfit. The first case results in an aerial accident within a short time of motor operation, whereas the second case - in very high motor overhaul costs.

This paper proposes a computer assisted method which allows a non-invasive assessment of the blade condition based on their surface colour. The first stage described in the article concerns the detection and positioning of the surface strictly related to the blade's leaf area, whereas the second stage concerns the colour analysis correlated with the microstructure testing of blades in various technical conditions (degree of overheating).

\section{SUBJECT OF TESTING AND RECORDING OF IMAGE DATA}

The digital images (photos) of gas turbine vane (blade) surfaces can be recorded in two ways:

- after the blade (vane) disassembly from the turbine; the recording device can include any digital camera with suitable repeatability and resolution of the obtained images;

- without blade (vane) disassembly; the recording device can include, e.g. a videoscope - devices for acquiring photos of hard to reach places.

The input images included photos of guide vanes disassembled from a gas turbine of an aircraft jet motor (Fig. 1). The vanes were made from the ŻS-6K alloy. An important technological aspect in these type of alloys is the thermal processing, which is based mainly on homogenising annealing (unification of the structure, increase in strength and ductility) [20]. The purpose of the processing is also obtaining the adequate dispersion and shape of precipitation of phase $\gamma^{\prime}$ as the main reinforcement phase. The coating is applying to allow increasing the working temperature, thereby additionally protecting the base material against harmful impact of the high temperature working medium (exhaust fumes). Figure 1a presents an exemplary set of recorded images of turbine vane surfaces with various degrees of overheating (acc. to the currently applied classification of their technical condition) with marked trailing and leading edges.

The input images were saved in the JPEG format with a low compression ratio preserving all necessary information and details about the recorded objects. In the case of this type of image data recording, it is possible to ensure high repeatability by determining fixed acquisition conditions (selection of a suitable light source and even lighting of the photographed surfaces, no reflections, etc.) - Fig. 1a. On the other hand, photos made using videoscopes (working conditions), due to the minimisation of the capture device's size and spot light sources, are encumbered by geometric distortion and colour corruption. Furthermore, the viewing device is movable and unstable, thus preventing exposure repeatability and even lighting of the tested elements (Fig. 1b, c). The fact that the tested element does not require disassembly from the turbine is undoubtedly an advantage of diagnostics using videoscopes.

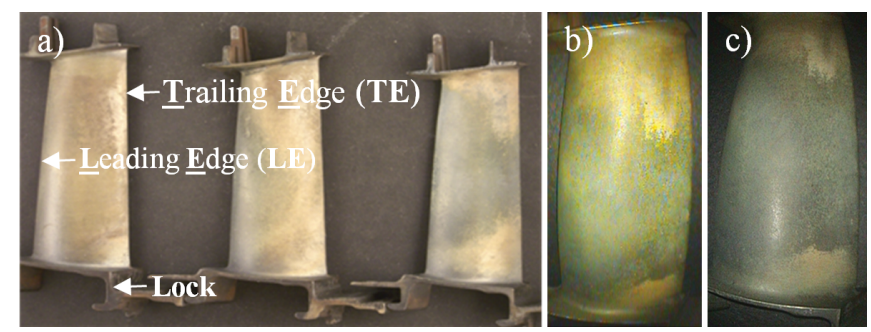

Fig. 1. Changes in vane surface colour recorded using various devices: a) image recorded at the measurement station using a camera; b) image recorded using the Olympus Iplex SA II videoscope; c) image recorded using the Everest XLG $3^{\text {tm }}$ VideoProbe videoscope 


\section{DETECTION OF VANES AND THEIR SURFACE ON A DIGITAL IMAGE}

This part of the paper will present subsequent steps of executing the automatic object (vanes - Fig. 3a) detection and positioning of the detected vane leaf surfaces based on images presenting optionally placed vanes with various technical condition. The execution of this task involves no human (user diagnostician) intervention. The block diagram of execution of subsequent stages of the selected image processing and analysis techniques and methods is presented in Fig. 2.

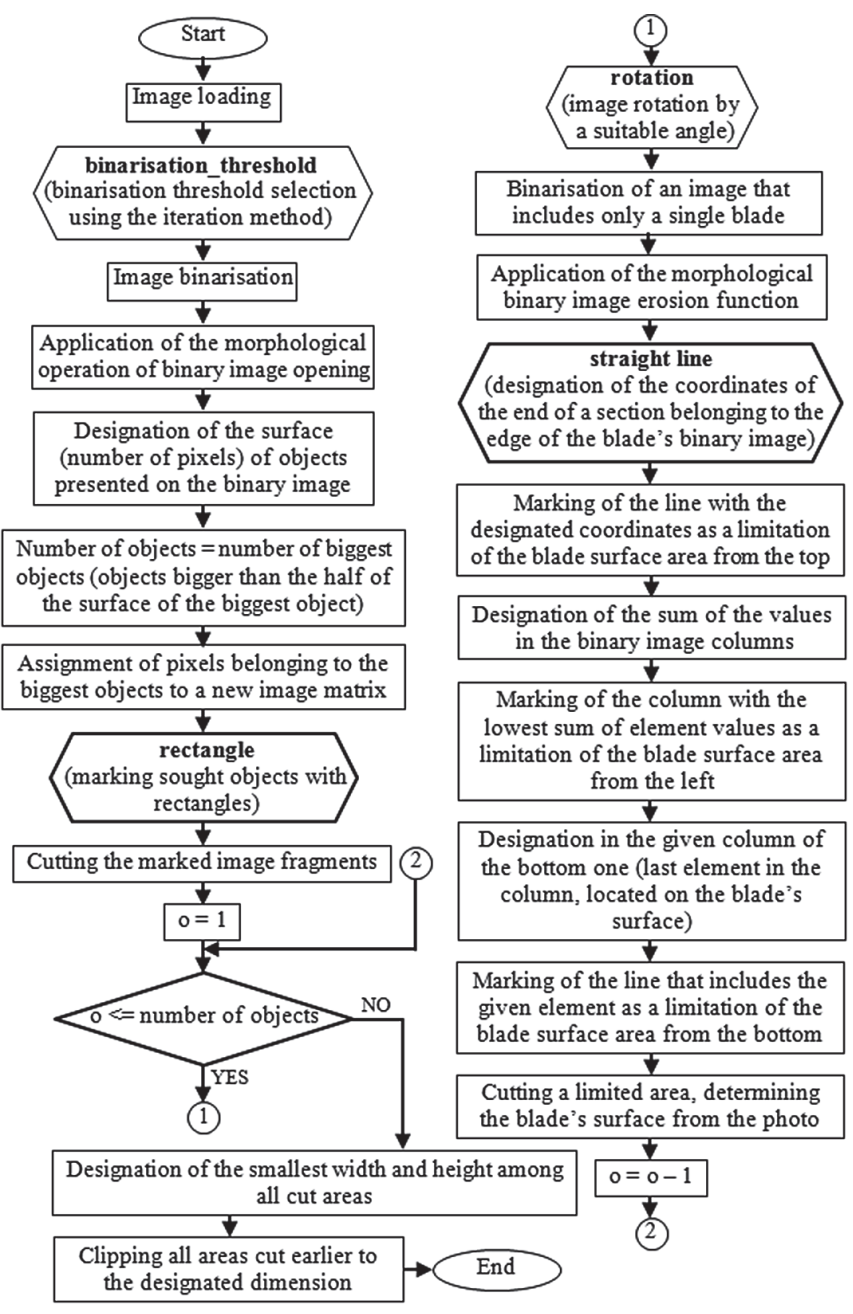

Fig. 2. Block diagram of the execution of subsequent steps of image processing and analysis - detection of vanes and their surface on a digital image

The input image (the example of such an image is presented in Fig. 3a) is firstly subjected to initial binarisation with the binarisation threshold selected using the iteration method, in accordance with the following steps [21]:

1. The extreme pixels (areas with the dimensions of $10 \times 10$ pixels selected on the photo's edges) are adopted as the background, while the other part of the image is adopted as the object. This served as the basis for designating the brightness of the background $\mu_{\mathrm{t}}$ and object $\mu_{\mathrm{o}}$. The threshold value is adopted in accordance with the following formula:

$$
T^{(0)}=\frac{\mu_{t}^{(0)}+\mu_{o}^{(0)}}{2}
$$

2. Designate the $\mathrm{n}$ average value for the background and object, while maintaining designated threshold. the pixel division to background and object

3. Designate a new threshold value:

$$
T^{(n+1)}=\frac{\mu_{t}^{(n)}+\mu_{o}^{(n)}}{2}
$$

4. Stop the algorithm when $T^{(\mathrm{n}+1)}=\mathrm{T}^{(\mathrm{n})}$, otherwise proceed to point (2).

where:

$\mathrm{T}^{(0)}$ - threshold value designated based on the initial assumptions,

$\mu_{t}^{(0)}$ - average value of the background designated based on the initial assumptions,

$\mu_{\mathrm{o}}{ }^{(0)}$ - average value of the object designated based on the initial assumptions,

$\mathrm{T}^{(0)}, \mu_{\mathrm{t}}^{(\mathrm{n})}, \mu_{\mathrm{o}}^{(\mathrm{n})}$ - values of the binarisation threshold, background average, object average, respectively, designated in subsequent algorithm iterations,

$\mathrm{n}$ - number of algorithm iterations.

The initial binarisation allows for separating the object pixels from the background pixels, however using it caused a large number of artefacts to be left on the binary image (Fig. 3b). They were removed by using the morphological function of binary image opening (with the structural element in the form of a disk with the size of 10 pixels); the effects of this operation are presented in figure $3 \mathrm{c}$. An additional advantage of executing the opening operation will be the separation of possibly combined or interfacing vane surfaces. The next step featured the indexation (labelling) of objects (vanes), thereby reducing the number of small objects that did not belong to the vane leaf's surface (mainly elements of the vane's lock) - Fig. 3d. As result of the executed operations (Fig. $3 \mathrm{c}$ and d), most artefacts, left from image binarisation (Fig. 3b), were removed, thereby preventing their impact on the dimensions of the designated surfaces (Fig. 3e). In figure 3e, the red colour was used to mark the smallest rectangles that completely surrounded particular detected objects (bounding box).
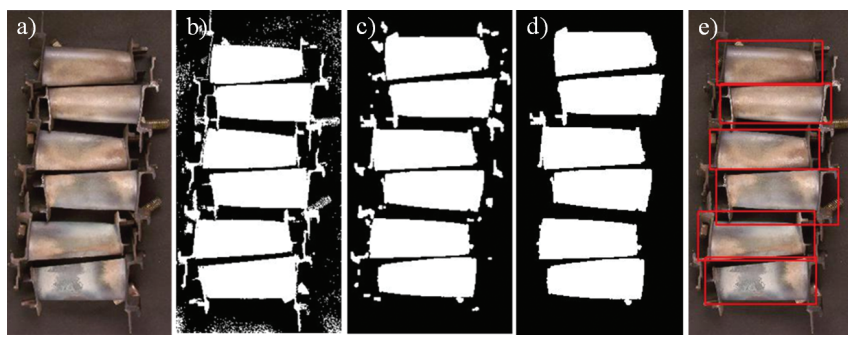

Fig. 3. Subsequent stages of vane detection on the recorded digital image: a) example of the original image; $b$ ) initial binarisation;

c) opening operation; d) reduction of small objects; e) correct detection of the turbine vane surfaces 
Due to the fact that the vanes in the digital image can be positioned in any configuration (position, number), the detected objects - surfaces (each rectangle from Fig. 3e is a new image cut from the original image in Fig. 3a) must be placed (positioned) in the same way (identical position of TE and LE).

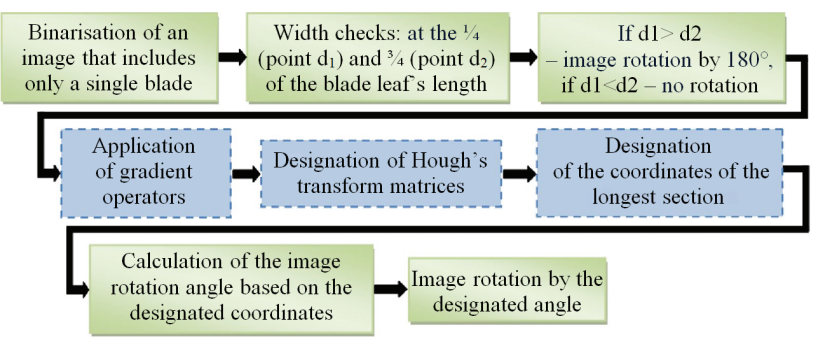

Fig. 4. Algorithm of automatic rotation of the vane surface with an isolated (blocks marked with a dotted line) procedure of section detection in the image

Therefore, the image fragments that include the detected surfaces were rotated, depending on the vane's position, by a suitable (designated) angle, thereby bringing all of them to a common reference frame. The general algorithm of automatic rotation is presented in Fig. 4. The position of the TE and LE for each vane was checked in the first step. Then, certain (selected) geometric features of the tested turbine elements were used to check the width at two positions: at $1 / 4$ and $3 / 4$ of the vane leaf's length (Fig. 5a). The dimensions comparison operation was executed on a binarised image fragment (Fig. 5b) - the sum of the values is designated in the right (dimension $\mathrm{d} 2$ ) and left (dimension $\mathrm{d} 1$ ) column. If $\mathrm{d} 2<\mathrm{d} 1$, the entire image is rotated by $180^{\circ}$. Thus, we obtained images on which vanes are positioned as assumed, i.e. TE upwards.

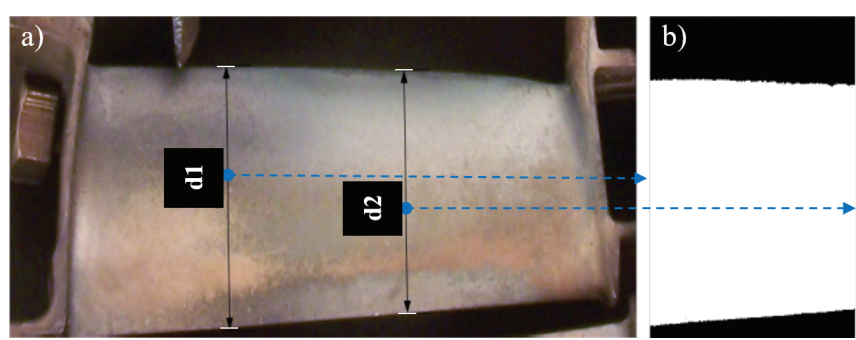

Fig. 5. Example of determination of differences in the vanes' geometry: a) compared vane dimensions;

b) the binary image presents the difference in the vane's width (dimension d1, d2)

Then, the vanes were rotated towards the horizontal plane in relation to the TE (for this purpose, two points belonging to it were designated). This was done by applying the gradient method of designating the object's edges (with Sobel's operator) and using the standard Hough's transform SHT) [6]. The designated edge was marked on the photo fragment using a section (Fig. 6).

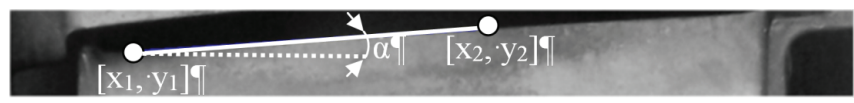

Fig. 6. Fig. 6. Section designated based on the Hough's transform
Despite the fact that the Sobel's operators (which allow for detecting vertical $h_{\mathrm{S} 1}$ and horizontal $h_{\mathrm{S} 2}$ lines - formula 3 ) are built based on Prewitt's operators, however in this case they strengthen the impact of the nearest pixel surroundings, for which the gradient is designated, resulting in obtaining more apparent contours than in the case of Prewitt's and Roberts' operators [9]:

$$
h_{S 1}=\left[\begin{array}{lll}
-1 & 0 & 1 \\
-2 & 0 & 2 \\
-1 & 0 & 1
\end{array}\right], \quad h_{S 2}=\left[\begin{array}{ccc}
-1 & -2 & -1 \\
0 & 0 & 0 \\
1 & 2 & 1
\end{array}\right]
$$

The automatic detection of the vane edges (straight lines) for particular fragments of the original image (new images that include only a single vane - object) was conducted using the SHT. based on the dependencies resulting from the SHT and on the points belonging to the section (Fig. 6), we designated the straight line's directional coefficient and the rotation angle $\alpha$ :

$$
\begin{gathered}
a=\frac{y_{2}-y_{1}}{x_{2}-x_{1}} \\
\alpha\left[^{\circ}\right]=\frac{180 \bullet \alpha[\mathrm{rad} / \mathrm{s}]}{\pi}
\end{gathered}
$$

After changing the vanes' configuration and rotation, we obtained images on which the vanes are positioned in an identical way. Then, while maintaining only the vane surface pixels (without the background pixels), it was necessary to cut the rectangles with the largest area possible from the images. Due to the fact that all fraction points were to be located within the area of the vane surfaces, we conducted an image binarisation with the threshold selected using the iteration method. Then, we used the morphological erosion method (with a square structural element with a 20 pixel size, thereby "reducing" the vane's surface) on the binary image. This operation allowed for further application of the gradient (Sobel's) operators and Hough's transform in order to designate the coordinates of two points belonging to the top (position of the edge on the photo) vane edge (blue section in Fig. 7).

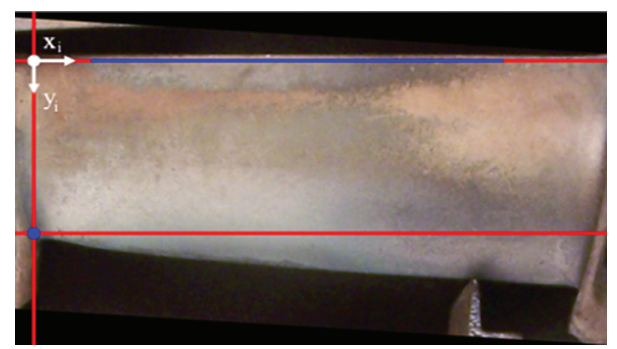

Fig. 7. Lines limiting the vane surfaces - sought (rectangular) area for further colour analysis

Thus, we were able to designate the straight line limiting the area later cut from the image for further analysis from the top (top red straight line in Fig. 7). The applied steps of 
procedure could not be used for designating the bottom straight line limited the sought area, because the leading edge line (bottom vane edge on the photo) is not a straight line, thereby making it probable that the designated straight line will not correctly limit the area.

This was also the reason for the calculation for the binary image of the sum in the image matrix columns (the vane area is white in the binary image - it has the value " 1 " in the image matrix), by selecting the column with the lowest sum value, we designated the position on the vane's length on which it has the smallest width. Thus, we obtained the straight line that limits the sought area from the left (red straight line on the left in Fig. 7). The bottom limitation of the sought image (bottom red straight line in Fig. 7) was obtained by locating in the earlier designated column of the last one, i.e. last column point belonging to the vane surface (from the top of the photo, blue point in Fig. 7).

The applied method did not guarantee identical dimensions cut out from the area photo, which is why the obtained rectangles were used to designate the smallest dimension of length and width, which was used as the basis for aligning (normalising) all cut out areas. As result, we were able to obtain image fragments with the same dimensions - surfaces (218x602 pixels). Figure 8 presents these fragments in the sequence corresponding to the vanes from the original photo (Fig. 3a), starting from the top. The black arrows in the figures designate the coordinates system that orients the positioning of the cut out fragments of vane photos.

The separated vane surface areas (Fig. $8 \mathrm{a} \div \mathrm{f}$ ) with various technical condition will undergo colour analysis correlated with the micro-structure testing both in the sub-surface zone and material of the vane and the coating.

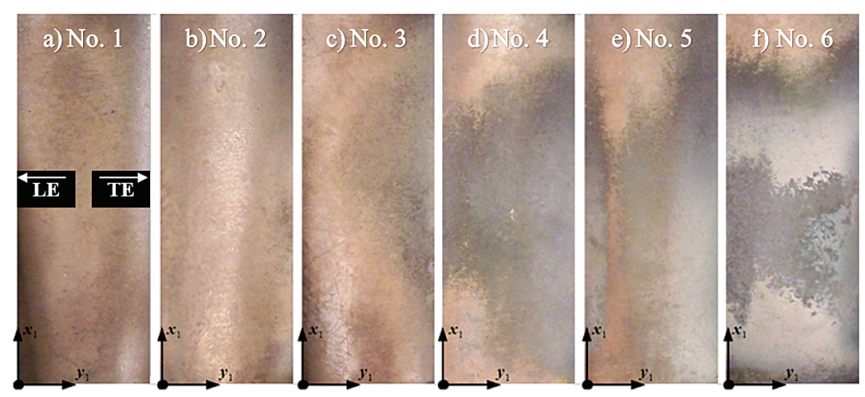

Fig. 8. Separated vane surface areas (various technical condition $a \div f$ )

\section{DIAGNOSING AND FORECASTING THE FAILURE OF OPERATED VANES}

The turbine vane (blade) durability is a sum of many factors, in which the material plays the crucial role. In terms of the material, durability can be defined as the time of operation, during which the alloy properties imparted during the manufacturing process remain stable. The stability of the properties (assumed working resource) is determined during the designing stage by selecting suitably high features (in comparison to the predicted loads and by analysing their changes during operation). The gas turbine vane (blade) destruction process starts with the deterioration of the aluminium coating (presented in the surface images in the form of colour scheme changes). The latter part of the paper will demonstrate the relation between the surface colour changes and its technical condition defined as the material criterion - material overheating (condition of vane coating, material - phase $\left.\gamma^{\prime}\right)[4,23,24]$. The method of procedure when developing the concept of computer-assisted assessment of the technical condition of used gas turbine vanes included several stages related to the recording of image data, selection of suitable colour representation (colour space), approach to notions related to colour analysis and metallographic testing. In the first step, various sets of used vanes were recorded with a digital camera on a specially designed station. The vane sets are a set of objects that differ in terms of their: number, position, technical condition (also resulting from their time of operation - vanes with increasingly longer times of operation). Then, in order to determine the impact of high temperature exhaust fumes during operation on the degradation of the vane surface and the micro-structure of the ŻS-6K super alloy, we conducted the metallographic testing. During the testing, the vane was divided into over a dozen parts, we conducted several measurements in locations of their most severe wear and colour profiles were drawn along the vane cutting lines. The micro-structure was examined under the Neophot optical microscope and the (SEM) Hitachi S-3000N scanning microscope. We characterised the vane deterioration process based on the metallographic testing. In the case of vanes permitted for exploitation (new vanes), the aluminiumsilicone surface layer is evenly distributed around the entire vane circumference. Furthermore, the layer consists of two sub-layers - external sub-layer with increased content of aluminium and intermediate layer with increased content of silicone, which also includes increased content of carbide formers (especially molybdenum and tungsten).

After analysing the technical condition of the coatings of used vanes from a turbine's jet crown (Fig. 9), it was established that after some time of operation the vane's coating does not degrade (Fig. 9a - vane no. 1 of fig. $8 \mathrm{a}$ ) and its thickness does not differ from the thickness of a new vane's coating. This condition of the coating is characterised by lack of any damage. After a longer time of operation, the coating undergoes expansion and features local surface damage (Fig. $9 \mathrm{~b}$ - the condition was observed incidentally on vane no. 3 from figure $8 \mathrm{c}$, its share increases in vanes no. $4,5,6)$. This condition of the coating is classified as partially fit for further use.

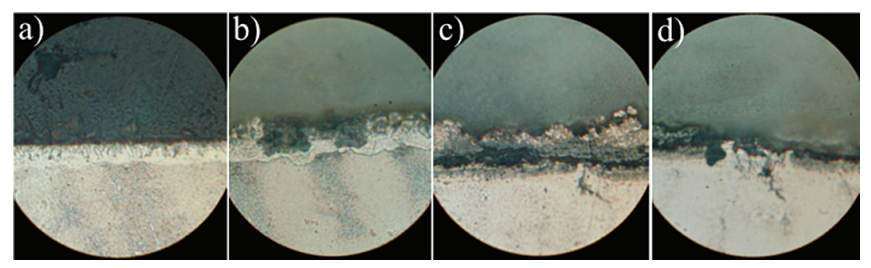

Fig. 9. Micro-structure of the coating of used polycrystalline turbine vanes (ŻS-6K alloy), $x 450$ zoom 
The expansion of the coating causes its delamination and cracking in the latter period of operation (Fig. $9 c-$ the condition was incidentally observed on the leading edge of vane no. 5 from figure 8e, while the biggest share of the condition was ascertained in vane no. 6 from figure $8 \mathrm{f}$ ). This type of damage causes local separation of the surface layer and cracking of the transitional layer diffused into the native material of the vane. In effect, within a short time of operation, the surface layer comes off and the crack penetrates deep into the vane's super alloy (Fig. 9d - vane no. 6 from figure 8f, mainly the area affected by the highest temperature, i.e. $1 / 3$ height of the vane's leaf). Damage in the form of coating delamination, local cavities in the surface layer and development of cracks result in its classification as an element that is unfit for further use. In the case of the vane material's micro-structure, it was ascertained that vane no. 6 is characterised by dispersive secondary separation of the phase $\gamma^{\prime}$, resulting from the impact of high temperature exhaust fumes. The morphology of phase $\gamma$ ' indicates that after exceeding the critical temperature, the alloy is overheated, and the turbine vane cannot be deemed as fit for further use $[4,23,24]$.

Figure $10 \mathrm{a}$ presents the line that represents the averaged colour profile (considering the cutting thickness, cuts parallel to the leading edge; the dotted lines mark cuts that are perpendicular to the leading edge). Considering the relatively high correlation of data - particular constituents of the RGB model (Fig. 10b) [2], the first step was to seek for a suitable representation of the image data, which would clearly reflect the colour changes of the vane surfaces. Among many models, i.e. HSV, CIEXYZ, CIELab, CMYK, etc., the largest differentiation in the image data (no correlation between particular constituents) was obtained for the $\mathrm{YCbCr}$ colour space model (Fig. 10c), the particular constituents of which, i.e. Y - luminance constituent, $\mathrm{Cb}$ - Y-B chrominance differential constituent (constituting the difference between luminance and blue colour) and $\mathrm{Cr}-\mathrm{Y}-\mathrm{R}$ chrominance differential constituent (constituting the difference between luminance and red colour), were designated based on the following conversion [17]:

$$
\left[\begin{array}{c}
Y \\
C b \\
C r
\end{array}\right]=\left[\begin{array}{ccc}
0,229 & 0,587 & 0,114 \\
-0,168 & -0,331 & -0,500 \\
0,500 & -0,418 & 0,082
\end{array}\right]\left[\begin{array}{l}
R \\
G \\
B
\end{array}\right]
$$

The parameters describing the constituents of the $\mathrm{YCbCr}$ colour space model were designated based on vane no. 1 . This vane is characterised by uniform colour and during the metallographic testing it was deemed as fit for use (correct technical condition, slightly deviating from a new vane). The method of procedure in relation to other vanes was identical to the vane presented in figure 10 (Fig. 10a dotted and continuous line - vane cutting, metallographic testing, drawing of colour profiles). Based on the exemplary results specified in figures $10 \mathrm{~b}$ and $10 \mathrm{c}$ it was ascertained that the waveform of constituent $Y$ (luminance), also in the case of vane no. 6 (multi-coloured surface), has a similar waveform (of changes) as constituents R, G, B presented in figure $10 \mathrm{~b}$.
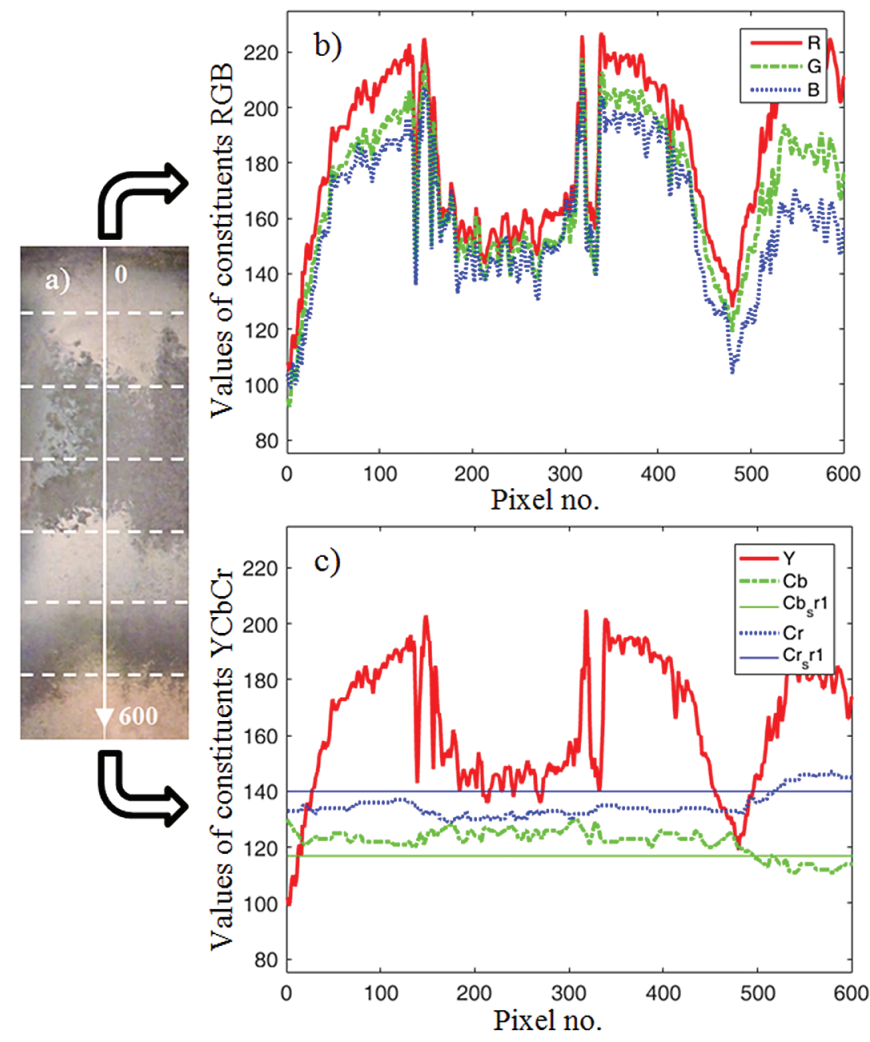

Fig. 10. a) vane cut; b) average pixel values along the cut line - RGB colours model; c) average pixel values along the cut line- $\mathrm{YCbCr}$ model

On the other hand, the chrominance constituents: $\mathrm{Cb}, \mathrm{Cr}$ demonstrate a different waveform characteristic. They were thus used to describe the colour changes taking place on the vanes' surfaces. In the case of vane no. 1, except for constituent Y (average value of Y_śr equal to 136, standard deviation $\mathrm{SD}$ equal to 10.1), the variability of $\mathrm{Cb}, \mathrm{Cr}$, drawn in a few colour profiles was minor (for $\mathrm{Cb}$ : $\mathrm{Cb} \_s r l=116, \mathrm{SD}=2.2$, for Cr: Cr_srl=140, SD=1.4). The sequences of obtained $\mathrm{Cb}, \mathrm{Cr}$ data included no values that would disrupt the designation of the average values. Figure $10 \mathrm{c}$ additionally presents the position of the average values describing the surface of vane no. 1 (Cb_srl, Cr_srl).

Based on the values of constituents $\mathrm{Cb}, \mathrm{Cr}$ for vane no. 1 and the nature of the waveform of these constituents in the colour profiles of vane no. 6, we designated the threshold values describing the non-overheated surface. The threshold value was designated for constituent $\mathrm{Cr}$ in the range from 140 to the maximum value, i.e. 255 (the other two constituents were not limited) - Fig. 11a

The result of the surface segmentation of vane no. 6 with limitation of constituent $\mathrm{Cr}$ is presented in figure $11 \mathrm{~b}$ (the area differing from the correct surface was dimmed by applying an operator). On the other hand, the range of the constituent $\mathrm{Cb}$ was modified in figure $11 \mathrm{c}$ (value range from 0 to 115). The result of the segmentation (limitation of the range of constituent $\mathrm{Cb}$ ) and marking of the overheated area 
is presented in figure 11d. On the other hand, figure 11e presents the resulting image with two limitations of the range of constituents $\mathrm{Cb}, \mathrm{Cr}$.

The surface with the correct condition in the case of vane no. 6: Fig. $11 \mathrm{~b}$ amounts to $11.34 \%$ of the total surface, Fig. 11d-9.89\%, Fig. 11e $-9.02 \%$ (double limitation slightly changes the percentage share of the surface).

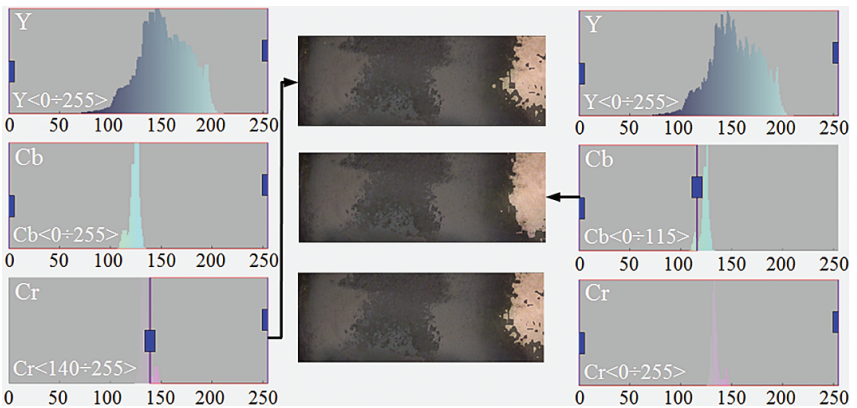

Fig. 11. Example of coloured surface segmentation of used vane marked as no. 6

(Fig. 9f): a) histograms of particular constituents of the $\mathrm{YCbCr}$ model (with a marked limitation of the range of constituent $\mathrm{Cr}$ ); b) result of segmentation (with emphasis on the non-overheated area - reduction of range $\mathrm{Cr}$ );

c) histograms of particular constituents of the $\mathrm{YCbCr}$ model (with a marked limitation of the range of constituent $C b$ );

d) result of segmentation (with emphasis on the non-overheated area) e) result of segmentation (double limitation of $\mathrm{Cb}, \mathrm{Cr}$ )

Figures 12a, c, e present the results of segmentation, including the surface classified as satisfactory for the exemplary set of vanes from figure 8 .
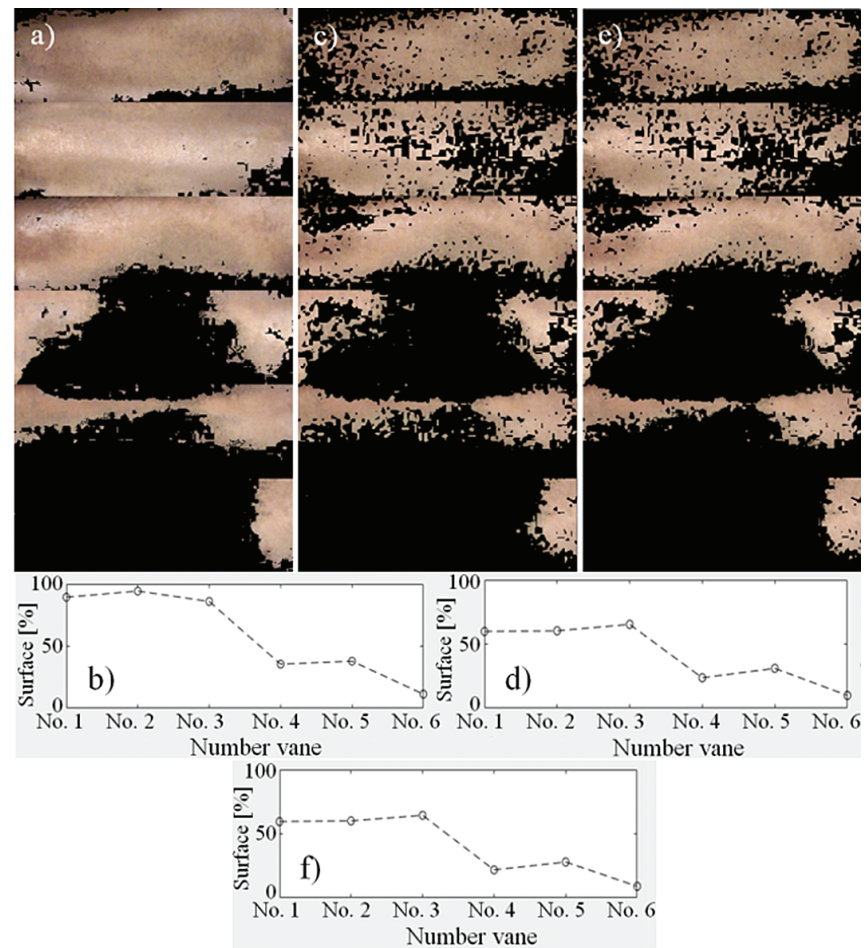

Fig. 12. Results of segmentation of the exemplary set of vanes (Fig. 8, no. $1 \div$ no. 6): a) surface images and $b$ ) percentage share of surfaces classified as satisfactory with the reduction of the range of constituent $\mathrm{Cr}$;

c) surface images and d) percentage share of surfaces classified as satisfactory with the reduction of the range of constituent $\mathrm{Cb}$;

e)surface images and $f$ ) percentage share of surfaces classified as satisfactory with the reduction of the range of constituents $\mathrm{Cb}$ and $\mathrm{Cr}$
Nearly identical results apply to figures $12 \mathrm{~d}$ and $12 \mathrm{f}$. The value fluctuations do not exceed $0.3 \%$, whereas the largest difference of $4.03 \%$ applies to vane no. 5 (12d - 27\%, $12 \mathrm{f}-31.03 \%)$. The differences in figures $12 \mathrm{a}, \mathrm{c}$, e result both from the colour scheme of the tested surfaces (vane no. 1, 2 "shades of yellow") and from the adopted method of determining the threshold values (average). The largest percentage share of surfaces classified as satisfactory, for particular vane numbers, was obtained with the limitation of constituent $\mathrm{Cr}$ (no. 1 $91.3 \%$, no. $2-94.25 \%$, no. $3-85.93 \%$, no. $4-35.54 \%$, no. 5 $37.94 \%$, no. $6-11.34 \%$ ) - Fig. 12b. The area that does not belong to the surface classified as satisfactory (black) also features the surface in transition (between satisfactory surface and overheated surface). It is characterised by a certain ambiguity due to the condition of the coating, the thickness of which increased (swelling of the surface layer and transitional layer), but the average thickness, due to the existence corrosion and erosion pitting, is lower than in the case of vanes no. 1,2 , but higher than in vane no. 6 (Fig. 9b). The structure (size, shape and distribution of separations of phase $\gamma^{\prime}$ ) deep into the vane material, only in extreme cases, at the transitional layer, slightly deviates from the model structure. The colour scheme of this surface is characterised by a different colour. Based on the metallographic testing combined with a colour analysis of the discussed type of surfaces, we determined the threshold values of segmentation for particular constituents, i.e. $\mathrm{Y}<58.160>$, $\mathrm{Cb}<112.119>, \mathrm{Cr}<0.138>$. The result of the segmentation is presented in figure 13a (orange - areas of surface in transition).

The share of surfaces in transition does not exceed (vanes no. $1 \div$ no. 6) $20 \%$ (Fig. 13b). The highest share concerns vane no. 5 and amounts to $16.5 \%$, whereas for vanes no. 1 and no. 2 , the share is miniscule and amounts to $3.25 \%$ and $2.5 \%$, respectively. A similarly low value applies to vane no. 6 (4.1\%). Figure $13 \mathrm{c}$ presents the share of the area (surface), the condition of which deviates from the satisfactory condition (the share of the surface in transition was also taken into consideration).

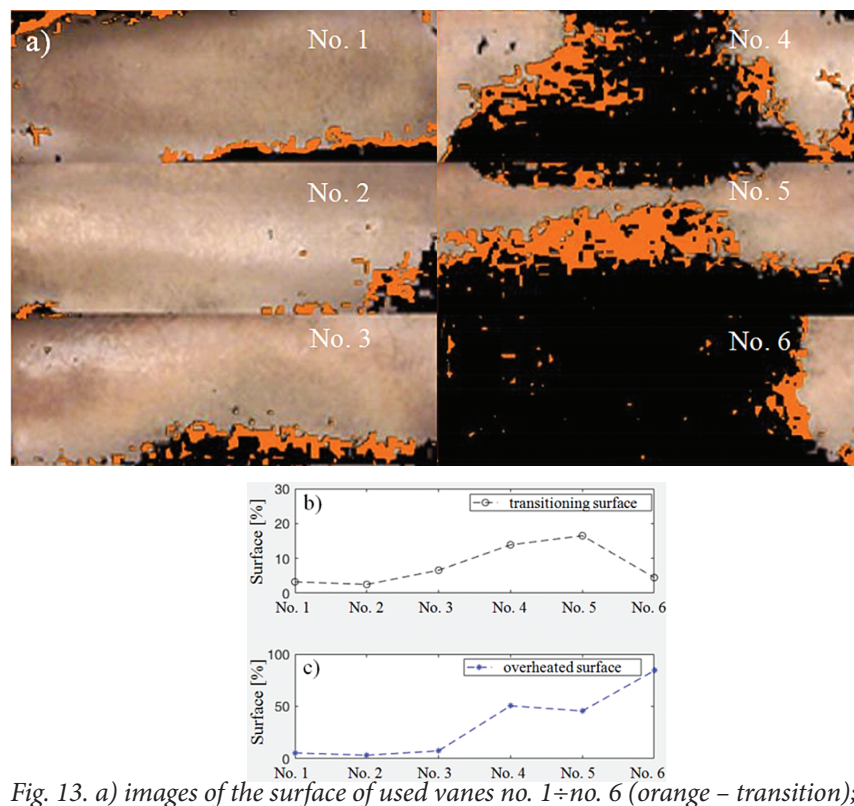
b) percentage share of these surfaces; $c$ ) percentage share of overheated surfaces 


\section{CONCLUSIONS}

The paper proposes the concept of computer-aided, noninvasive method of assessment of the condition of operated vanes (blades) based on the colour of their surface. The described approach embraces several stages. The first stage concerns the detection of the surface (strictly determined and related to the area of the blade's leaf), which is then subjected to colour analysis in the next stage. The first stage concerns the detection of the surface (strictly determined and related to the area of the vane's leaf), which is then subjected to colour analysis in the next stage. The verification of the technical condition of used vanes was conducted using a destructive method on metallographic samples. The metallographic testing concerned the assessment of the coating's condition and the characteristics of the separation of phase $\gamma^{\prime}$ (both in the vane's surface layer and in its material). The material criterion was correlated with the colouristic changes on the vanes' surface. Based on the colour profiles, we were able to determine the threshold values describing particular colour ranges (histograms of constituents of the $\mathrm{YCbCr}$ model) representing an overheated, nonoverheated vane and vane in transition. The most satisfactory results were obtained in the case of determining the range of values for constituent $\mathrm{Cb}$ (the determined range of constituent $\mathrm{Cb}$ includes the largest colouristic differentiation of the tested surfaces with simultaneous maintenance of the correctness of the obtained results - this thesis was confirmed by metallographic testing). Based on the results of the analysis of the vane surface images, it is possible to conclude that vanes no. 1, 2 and 3 are satisfactory, because the percentage share of the surface classified as satisfactory and in transition (with minimum share of this condition amounting to $3.25 \%, 2.5 \%$, $6.25 \%$, respectively) fluctuates around 95\% (Fig. 13c). On the other hand, vanes no. 4, 5, 6 are overheated, because the percentage share of the overheated surface and surface in transition (in the case of vanes no. 4 and 5, with a substantial percentage share amounting to $13.87 \%$ and $16.5 \%$ ) substantially differs from the aforementioned vanes, and the overheated surface for particular vanes is as follows: no. 4 - over $50 \%$, no. 5 - over $45 \%$, no. 6 - over $80 \%$ (Fig. 12 a, 13 b, c).

In some cases, the diagnostics of the condition of vanes (blades), aside from the strict classification of "element fit for use - element unfit for use", features a third assessment of the condition, referred to as a "partially fit element". This condition requires periodical diagnostics (the vane (blade) undergoes periodical diagnostics until it is unfit for further use). In the case of the proposed assessment of the technical condition, it is possible to deem a vane (blade) "with a certain share" of transition and miniscule share of surface deemed as overheated as a "partially fit element" (it, however, requires further testing; further specification). Furthermore, the results presented in figure $13 \mathrm{~b}$, providing information concerning the surface area in transition can contribute to the determination of the time within which the given object will conditionally maintain its properties (observation of the vane deterioration process during periodical diagnostics). Therefore, the development of a surface area in transition or its complete transition into an unfit condition can constitute prerequisites for estimating the assumed and actual conditions of vane (blade) operation, particularly since their time of operation increases, thereby leading to the vanes' critical condition in the estimated range of load.

\section{REFERENCES}

1. Balicki W., Szczeciński S.: Diagnosing aircraft turbine engines (in Polish). Maszyny wirnikowe. Biblioteka Naukowa Instytutu Lotnictwa. Warszawa 2001.

2. Błachnio J., Bogdan M.: A non-destructive method to assess condition of gas turbine blades based on the analysis of blade surface image. Russian Journal of Nondestructive Testing, 46 (2010), pp. 860-866.

3. Błachnio J., Bogdan M., Kułaszka A.: New non-destructive methods of diagnosing health of gas turbine blades, in: by E. Benini (eds.). Advances in Gas Turbine Technology 2011. InTech, pp. 465-498.

4. Błachnio J., Bogdan M., Zasada D.: Increased temperature impact on durability of gas turbine blades. Eksploatacja i Niezawodnosc - Maintenance and Reliability 19(1) (2017) pp. $48-53$.

5. Crostack H. A., Padmapriya N.: NDT of coatings, surface modified layers, and adhesives. Reference Module in Materials Science and Materials Engineering. Elsevier, 2016.

6. Duda R. O., Hart P. E.: Use of the Hough Transformation to detect lines and curves in pictures. ACM, 15 (1972), pp. 11-15.

7. Giampaolo G. T.: Turbine Handbook: Principles and Practice (5th Edition). Lilburn (Georgia): Fairmont Press, 2013.

8. Girtler J., Dzida M.: Operation evaluation method for marine turbine combustion engines in terms of energetics. Polish Maritime Research 23, 4(92) (2016), pp. 67-72.

9. Gonzales R. C, Woods R. E.: Digital Image Processing. 2nd ed. Englewood Cliffs, NJ: Prentice-Hall, (2002).

10. Grządziela A.: Analysis of vibration parameters of ship gas turbine engines. Polish Maritime Research, 2 (2006), pp. 22-26.

11. Korczewski Z.: Endoscopic examination of naval gas turbines. Polish Maritime Research, 4 (1998), pp. 13-16.

12. Korczewski Z.: Exhaust gas temperature measurements in diagnostic examination of naval gas turbine engines. Polish Maritime Research, 18(2) (2011), pp. 37-43. 
13. Korczewski Z.: Operational causes offatigue failures within passages of gas turbine engines. Polish Maritime Research, 17 (2010), pp. 57-61.

14. Lewitowicz J., Kowalski M., Żyluk A.: Modern diagnostics of aircraft gas turbine engines - some selected issues. Journal of KONBiN, 29(1) (2014), pp. 33-40.

15. Matzkanin G.A.: Selecting a nondestructive testing method: visual inspection. Advanced Materials, Manufacturing and Testing Information Analysis Center 1(3) (2006), pp. 7-10.

16. Pitkänen J., Hakkarainen T., Jeskanen H., Kuusinen P., Lahdenperä K., Särkiniemi P., Kemppainen M., Pihkakoski M.: NDT methods for revealing anomalies and defects in gas turbine blades. Proc 15th WCNDT, Rome 43 (2001), pp. 601-604.

17. Poynton C.: A guided tour of color space new foundations for video technology. Proceedings of the SMTPE Advanced Television and Electronic Imaging Conference (1995), pp. 167-180.

18. Raj B., Thavasimuthu M., Jayakumar T.: Practical nondestructive testing, 3rd eds. New Delhi, India: Narosa Publishing House, 2014.

19. Rajendran R., Ganeshachar M.D., Rao T. M., Condition assessment of gas turbine blades and coatings, In: Engineering Failure Analysis, 18 (8) (2011), pp. 2104-2110.

20. Reed R. C.: The Superalloys fundamentals and applications. Cambridge: Cambridge University Press, 2006.

21. Ridler T., Calvard S.: Picture thresholding using an interactive selection method. IEEE Trans. System, Man and Cybernetics, SMC, 8(8) (1978), pp. 630-632.

22. Soares C.: Gas Turbines: A Handbook of Air, Land and Sea Applications (Second Edition), Butterworth-Heinemann, Oxford, 2015.

23. Sujata M., Madan M., Raghavendra K., Venkataswamy M. A., Bhaumik S. K.: Identification of failure mechanisms in nickel base superalloy turbine blades through microstructural study. Engineering Failure Analysis 17(6) (2010), pp. 1436-1446.

24. Tresa M. Nickel-based superalloys for advanced turbine engines: chemistry, microstructure and properties. J. Propuls. Power 22(2) (2006), pp. 361-374.

\section{CONTACT WITH THE AUTHOR}

\author{
Mariusz Bogdan \\ e-mail:m.bogdan@pb.edu.pl \\ Bialystok Technical University \\ Wiejska 45 \\ 15-333 Białystok \\ POLAND \\ Marcin Derlatka \\ e-mail:m.derlatka@pb.edu.pl \\ Bialystok Technical University \\ Wiejska 45 \\ 15-333 Białystok \\ Poland \\ Józef Błachnio \\ e-mail: jozef.blachnio@itwl.pl \\ Air Force Institute of Technology \\ Księcia Bolesława 5 \\ 01-494 Warszawa \\ Poland
}

